\title{
Experimentation of a new type of permissible explosive under the specific conditions of the Jiu Valley mines
}

\author{
Robert Laszlo ${ }^{1}$, Emilian Ghicioi ${ }^{1}$, Cristian Radeanu ${ }^{1}$, Bogdan Garaliu Busoi ${ }^{1}$, and Stefan \\ Ilici $^{1}$ \\ ${ }^{1}$ National Institute for Research and Development in Mine Safety and Protection to Explosion - \\ INSEMEX, Department Security of Explosives and Pyrotechnic Articles, 32-34 G-ral Vasile Milea \\ Street, 332047 - Petrosani, Romania
}

\begin{abstract}
At the underground mining works performed in coal, rock and mixed coal \& rocks, the process applied almost exclusively is by drilling \& blasting. Given that the mines in the Jiu Valley are classified as methane mines, this involves the use of explosives and means of initiation that are safe from methane gas and coal dust. To date, permissible powdered explosives have been widely used. The drilling \& blasting patterns were established according to the physical - mechanical and geological characteristics of the rocks in the massif, the type and section of the mining works as well as the restrictions imposed by the methane regime of the mines. In recent years, the widespread use of emulsion explosives has led to the development of permissible types of emulsion explosives. In order to use the permissible emulsion in the coal mines in the Jiu Valley, it was necessary to test in the INSEMEX landfill the safety and functioning parameters as well as to perform underground blasts, in the specific conditions of the methane coal mines. The paper describes the underground experimental blasting works performed, as well as technical and safety recommendations for the use of this type of explosive - permissible emulsion.
\end{abstract}

\section{Introduction}

The manner of performing the blasting works in the mines with methane gas regime has been regulated over time by a series of normative acts that are the basis of the security measures and requirements established by the mining units that carry out their activity in such conditions.

In the mines in the Jiu Valley, the excavation of mining works in rock, coal and mixed coal \& rocks is done almost exclusively with the help of explosives, through the drilling \& blasting process. Depending on the relative flow of methane and its release, the coal mines in the Jiu Valley are classified in the second category as mines with "methane regime" (over $15 \mathrm{~m}^{3} / \mathrm{ton}$.), which led to the establishment additional security requirements imposed on blasting technologies and explosive materials.

\footnotetext{
* Corresponding author: robert.laszlo@insemex.ro
} 
Regarding the explosive materials and the initiating means, one of the main safety requirements is their safety against the air-methane and air-methane-coal dust mixture, respectively the reduction of the risk of ignition of these mixtures.

Over time, various explosive materials have been used in the mines in the Jiu Valley, either ordinary (dynamite) when digging mining works in rocks, or permissible (AGC, AGP, Metanit Special, etc.) when digging coal mining works.

Today, for safety reasons, at the digging of all types of mining works, only permissible explosives and initiation means are used. The permissible explosives used are of the powder type - Metanit Special E7H, millisecond electric detonators type MMSED - Cu, with 18 delay stages and a delay interval of $30 \mathrm{~ms}$ between two consecutive steps, respectively permissible detonating cord type RIOCORD PS with 6 gr./lm. load $[1,2]$.

Given that at the end of this year the Metanit Special E7H explosive will no longer be available on the market, the supplier proposed to replace it with an emulsion type of permissible explosive - Emulinit PM.

The use of the new type of explosive involved its additional verification in laboratory conditions - in terms of safety parameters against methane and coal dust as well as underground experimentation, in order to establish the appropriate drilling $\&$ blasting parameters.

For this purpose, a program for testing the safety parameters in the Explosives Polygon of INSEMEX Petrosani was carried out, as well as a number of 40 underground experimental blasts at the Vulcan and Livezeni mines.

\section{Methodology}

\subsection{Aspects regarding the safety requirements of permissible explosives}

Only safety explosives and means of initiation are used for the blasting works in coal mines according to the provisions of Law 126/1995, with the subsequent amendments and completions brought by the existing legislation in force as well as according to GD 1049/2006 regarding the regime of explosive materials.

Permissible explosives shall be used only after the production batch has been tested and certified by a notified body for that purpose.

For this purpose, the test is performed in a mortar with a central channel, in an atmosphere of air - methane $(9.0 \pm 1.0 \%$ volume $)$, respectively air - methane ( $4.0 \pm 0.5 \%$ volume $)$ - dust of coal (in suspension $330 \mathrm{gr} . / \mathrm{m}^{3}$ and in the mortar channel $50-150 \mathrm{gr} . /$ test), is $1.000 \mathrm{grams}$, and the maximum load allowed for underground use in the mine hole is limited to 800 grams.

Production batches of permissible millisecond electric detonators are used, whose possibility of igniting the air - methane atmosphere at a volumetric concentration of 8-10\% $\mathrm{CH} 4$, is less than $4 \%$ of the total number of tested detonators.

\subsection{Peculiarities regarding the execution of the blasting works in the coal mines}

\subsubsection{Requirements for blasting technologies}

When determining the requirements for blasting technologies, the factors involved must be taken into account, such as the regime of methane gas emissions and the flammability of coal dust.

In order to ensure the safe and efficient blasting operations, the following major requirements are highlighted $[2,3]$.

- the distance between the holes corresponding to the type of rock and the explosive (minimum $0.5 \mathrm{~m}$ ), in order to avoid the destruction of the tightness state of the explosive charges 
in the delayed firing process and the occurrence of the risk of amputation and unloading of the explosive charges;

- correlation of the hole length with the length of the explosive charge and with the observance of the minimum stemming length (minimum $1 / 2$ of the hole length);

- proper initiation of explosive charges by ensuring a delay interval of $75 \mathrm{~ms}$ between two adjacent holes capable of influencing each other, respectively ensuring between the first and last charge that can be fired in the blast face of a delay interval of $200 \mathrm{~ms}$ in coal and $400 \mathrm{~ms}$ in other rocks;

- observance of the optimal ratio between the diameter of the mine hole and that of the explosive cartridges $(10-25 \%)$;

- rear priming of the explosive cartridge inserted in the mine hole;

- when establishing the maximum quantity of explosive possible to be detonated in a mining work, the necessary air flow at the work place will be taken into account according to the criterion of diluting the gases resulting from the firing operation.

\subsubsection{Drilling and blasting parameters}

Achieving the desired blasting effects is conditional on setting the parameters of the blasting works so as to ensure the detachment of the rock from the massif, reducing over profiling and cracking area, obtaining an optimum granulometry and a reduced spread of the blasted rock mass $[4,5]$.

This presupposes that the drilling and blasting parameters are determined in correlation with the physical - mechanical characteristics of the rocks and the thermodynamics of the explosives used, respectively $[4,5]$ :

- physical-mechanical and elastic properties, respectively natural fragmentation (on micro and macrocrystalline scale) of rocks;

- the section of mining works in the excavation;

- number of free surfaces of the blasting front;

- drilling and blasting parameters;

- type of explosives and initiation means;

- type of explosive load;

- size and quality of stemming area.

In the conditions of digging mining works with a single free surface - the most common situation in the case of coal mines in the Jiu Valley, the action of the explosion is oriented towards this surface, on the line of least resistance, because only in this direction the massif has the possibility to deform indefinitely.

The correct formation of the blasting cut is an essential factor in increasing the degree of dislocation of the rock in the massif, in the situation of the existence of a single free surface. Considering the endowment of the mining units with means for drilling the mine holes and the physical-mechanical characteristics of the rocks in the massif, the converging blasting cuts are widely used [1].

They are drilled perpendicular to the stratification or cleavage of the front rocks, approaching in depth at a distance of 0.1- 0.3 m., having a length greater than the rest of the holes in the front, so that the plane passing through the base of the convergent holes to be in front of the plane passing through the base of the stopping and profiling holes by $0.1-0.2 \mathrm{~m}$.

Figure 1 shows a blasting pattern with 48 holes for a transverse gallery dug in rocks, with the size of $4.3 \times 3.25 \mathrm{~m}$ and in Figure 2 a blasting pattern with 42 holes for a directional gallery dug in rocks, with the size of $3.8 \times 2.8 \mathrm{~m}$. 

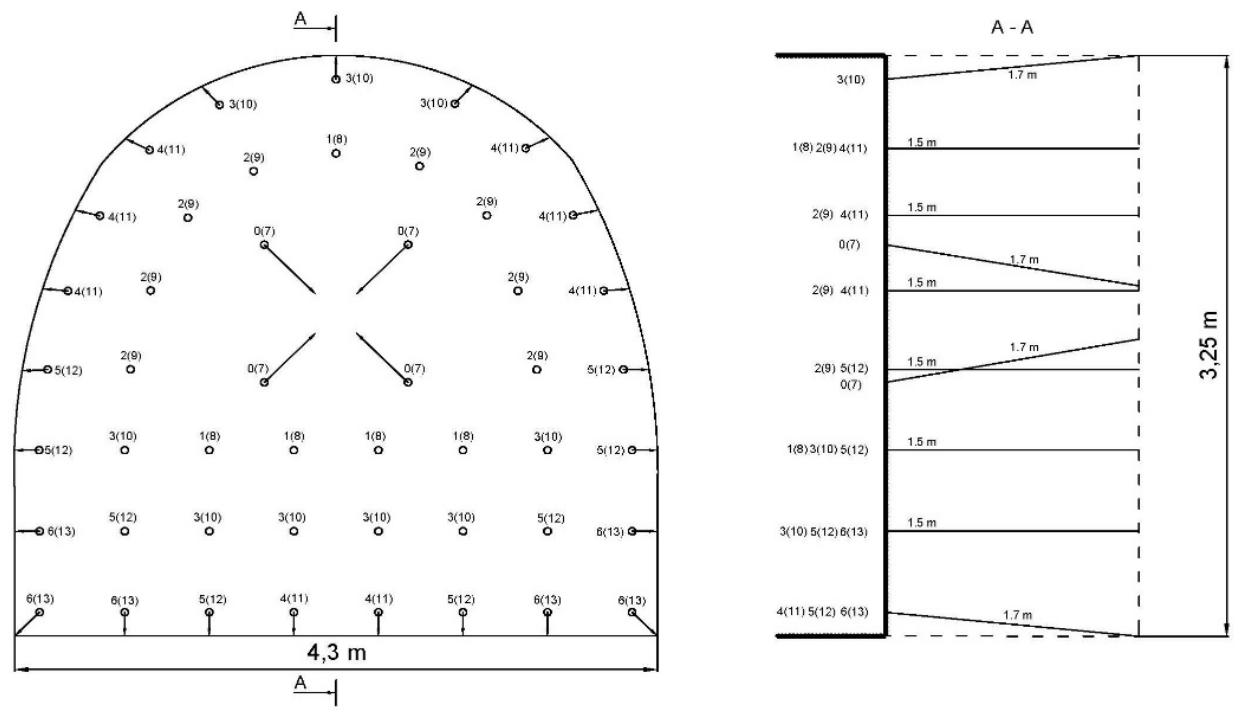

Fig. 1. Blasting pattern with 48 holes for digging gallery in rocks.
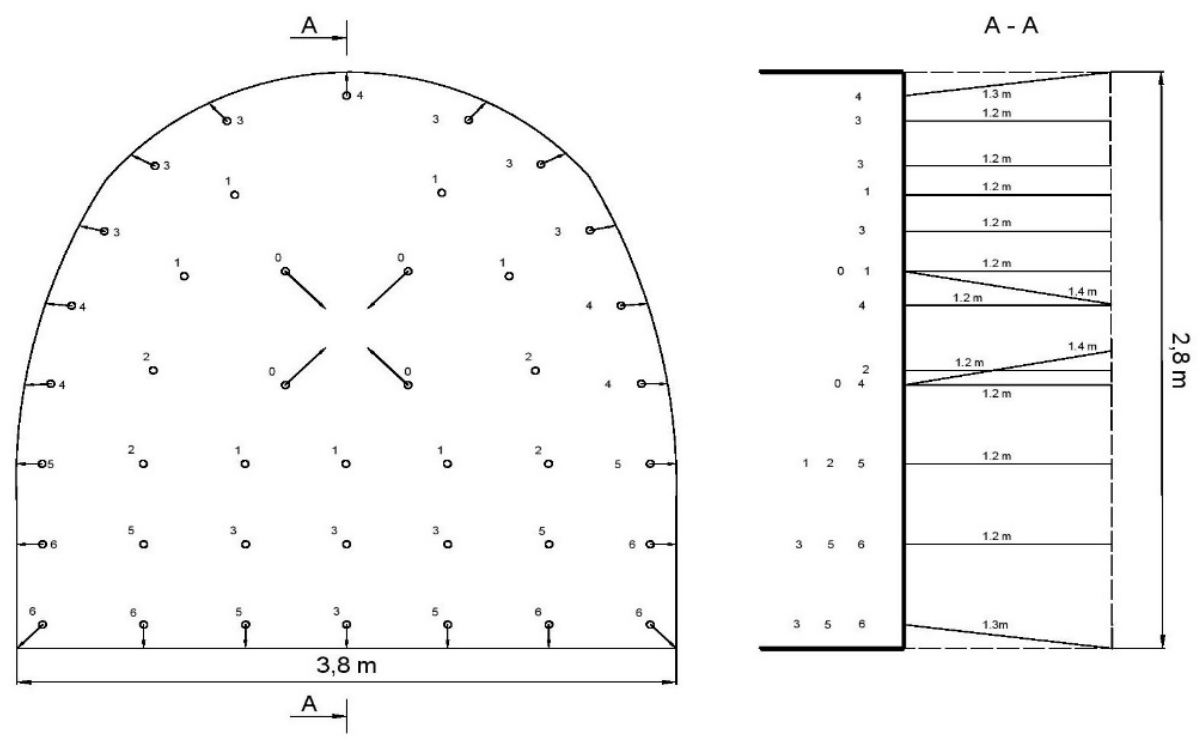

Fig. 2. Blasting pattern with 42 holes for digging gallery in rocks.

The widening holes are placed around the cut holes so as to ensure a sufficient density on the front surface, which allows the extension of the free space created by the cut holes. When choosing the number of stopping and profiling holes as well as their location, the strength and friability of the rock in the massif are taken into account. In Figure 3 is presented a blasting pattern with 36 holes for a directional gallery dug in mixed rocks, with a size of $3.8 \times 2.8 \mathrm{~m}$. 

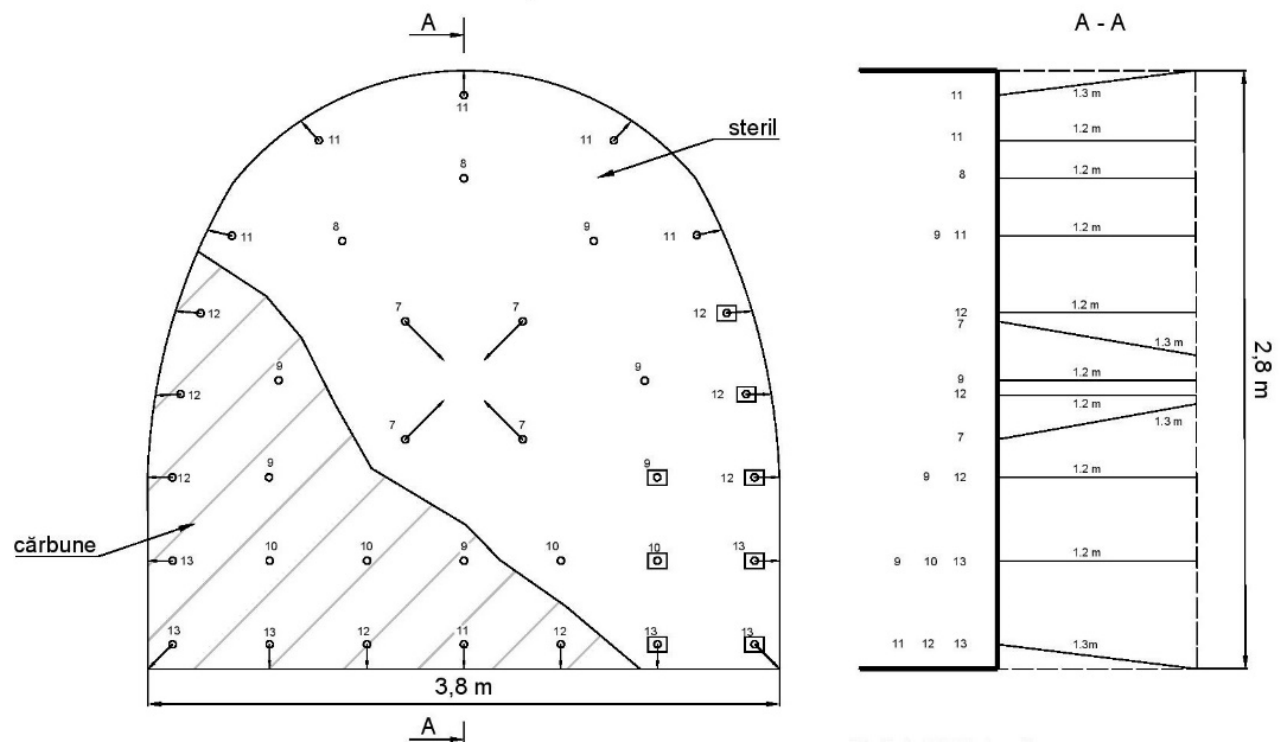

Fig. 3. Blasting pattern with 36 holes for digging gallery in mixed rock \& coal.

Profiling holes are located as close as possible to the projected contour of the mining work $(0.1-0.2 \mathrm{~m})$ so as to avoid over profiling of the mining work.

The mining works are excavated in rock, coal and mixed rock \& coal. The support of these works is made with sliding metal arches made of laminated profiles, arranged in fields of 0.5 $1.0 \mathrm{~m}$.

Regarding the blasting works at the long walls, depending on the strength of the coal in the work front, patterns with one or two rows of mine holes are applied. In the case of low-strength coal, the firing pattern with one row of holes is used, in which case the orientation of the holes is towards the bottom side of the long wall.

In the situation where the coal from the long wall front has a high friability, the cutting of the coal at the front is done exclusively by pneumatic hand hammer.

For the removal of the coal with medium to high strength, the blasting pattern with two rows of holes is applied, in which the holes in the upper row are oriented perpendicular to the transverse plane of the long wall (Figure 4). The arrangement of the holes on each row is done in the same horizontal plane, between the rows of beams, but in different vertical (directional) planes.

In order to achieve the desired length of advance $(1.1-1.2 \mathrm{~m})$, corresponding to a breaking efficiency of the explosive with a ratio of $0.7-0.8$, the length of the inclined holes is $1.5-1.7 \mathrm{~m}$, being oriented towards the bottom side of long wall, respectively $1.3-1.5 \mathrm{~m}$ for those oriented perpendicular to the front.

Regardless of the drilling pattern adopted, the holes are blasted sequentially, on short sections of $5-7 \mathrm{~m}$ length. Regarding the order of initiation of holes and rows of holes, in the first steps are initiated the holes in the second row, starting from the central area of the section, to the extremities, followed by holes from the first row and which are similarly initiated, starting from the central area to the extremities (Figure 4).

The undisplaced coal, located at the top of the long wall face, is dug out with the pneumatic hand hammer. 

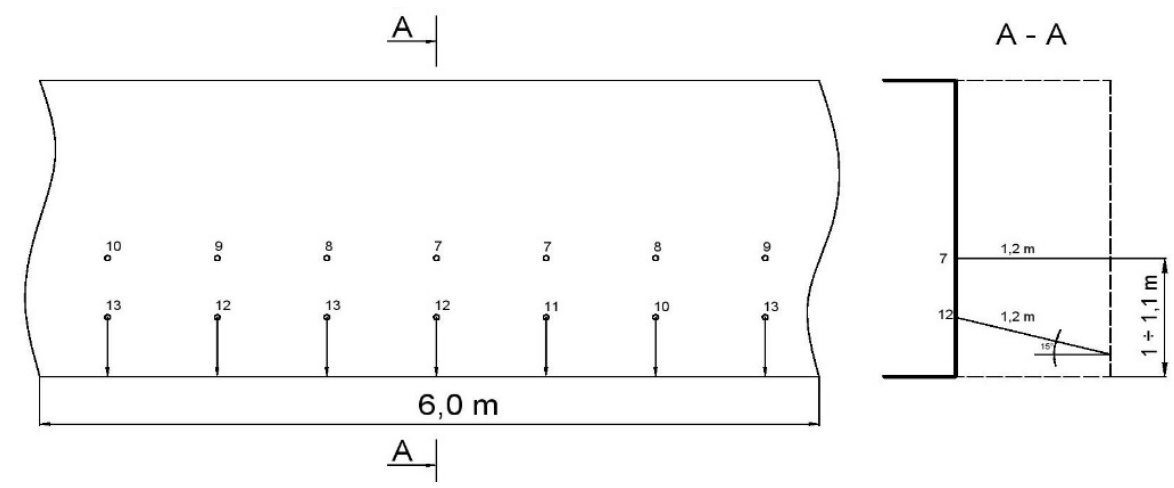

Fig. 4. Blasting pattern for coal long wall.

\section{Results and discussions}

In order to use the new permissible emulsion type of explosive - Emulinit PM in the coal mines from the Jiu Valley, it was necessary to check the safety parameters in the Explosive Polygon of Insemex Petrosani.

Also, an underground experimentation program was prepared by using the explosive Emulinit PM for the blasting works in the galleries as well as in the coal long walls, having as reference point the parameters and the current blasting patterns practiced and presented at point 2.2 .

Given the differences in size and weight of the current explosive cartridge used - Metanit Special E7H compared to the new explosive - Emulinit PM (Table 1), in the experimental blasting work was particularly aimed to establish the maximum amount of explosive in the mine hole correlated with the performance of the blasting work and the ventilation requirements in the work fronts.

\subsection{Tests on the safety parameters of the Emulinit PM explosive}

Explosive emulsions are a mixture of aqueous ammonium nitrate solution, various liquid fuels, emulsifiers, sensitizers and components that ensure the transmission of detonation in the mixture.

Emulsion explosives are based on the "water in oil" principle. In the composition of such an explosive, as an oxidant, ammonium nitrate $(60 \div 85 \%)$ is used as a solution (water proportion of $8 \div 16 \%$ ), and mineral oils are used as fuel, in a concentration of $5 \div 7 \%$.

In Table 1 are compared different parameters such as physical-mechanical, ballistic or safety between the Metanit Special E7H and Emulinit PM permissible explosives. Analyzing the data in Table 1, we can observe some significant differences between the two explosives, i.e., detonation speed, shock sensitivity, mass and length of the explosive cartridge.

Table 1. Comparation between Metanit Special E7H and Emulinit PM

\begin{tabular}{|c|c|c|c|}
\hline \multirow{2}{*}{ Explosive parameters } & \multirow{2}{*}{ M.U. } & \multicolumn{2}{|c|}{ Explosive type } \\
\cline { 3 - 4 } & & Emulinit PM & Metanit Special E7H \\
\hline 0. & 1. & 2. & 3. \\
\hline I. Physico - chemical parameters: & & & \\
- $\quad$ appearance / color; & & Emulsion $/$ white & Powder/green \\
- density, minim; & $\mathrm{gr} / \mathrm{cm}^{3}$ & $1.15-1,21$ & 1.12 \\
- $\quad$ humidity, maxim; & $\%$ & 5.5 & 1.5 \\
$\bullet \quad$ stability at $75^{\circ} \mathrm{C}$, minim; & hours & 48 & 48 \\
\hline
\end{tabular}




\begin{tabular}{|l|c|c|c|}
\hline II. Ballistic parameters: & & & $\geq 2,000$ \\
- detonation; & $\mathrm{m} / \mathrm{s}$ & $>4,000$ & 6 \\
- transmission of detonation; & $\mathrm{cm}$ & 6 & 160 \\
- $\quad$ work capacity (Trauzl test); & $\mathrm{cm}^{3}$ & 178 & - \\
- brisance (Hess test); & $\mathrm{mm}$ & - & 1,0 \\
- equivalence coefficient in & & 1,0 & \\
$\quad$ TNT; & & & $\geq 5$ \\
\hline III. Safety parameters: & $\mathrm{J}$ & $\geq 50$ & $>324$ \\
- $\quad$ sensitivity to shock; & $\mathrm{N}$ & $>360$ & $-10 \div 50$ \\
- $\quad$ maxitivity to friction; & ${ }^{\circ} \mathrm{C}$ & $-10 \div 50$ & $0 \div 30$ \\
$\quad$ temperature; & ${ }^{\circ} \mathrm{C}$ & $0 \div 30$ & \\
- storage temperature; & & & 32 \\
\hline IV. Other parameters: & & & 140 \\
- diameter; & $\mathrm{mm}$ & 32 & 125 \\
- cartridge length; & $\mathrm{mm}$ & 300 & 4.4 \\
- cartridge weight; & $\mathrm{g}$ & 300 & 6 \\
- oxygen balance; & $\%$ & -8.53 & 6 \\
- shelf life; & $\mathrm{month}$ & 6 & \\
\hline
\end{tabular}

As a peculiarity of the Emulinit PM explosive is the fact that in the situation where in the practical applications a certain quantity / length of explosive is needed in the mine hole and that does not fall in a multiple of 300 gr. or $300 \mathrm{~mm}$, it can be sectioned manually in the middle of the cartridge, in the area indicated by the two arrows marked on the package (Figure 5). In this way you get two cartridges with a mass of 150 gr. and length of $150 \mathrm{~mm}$. each of them.

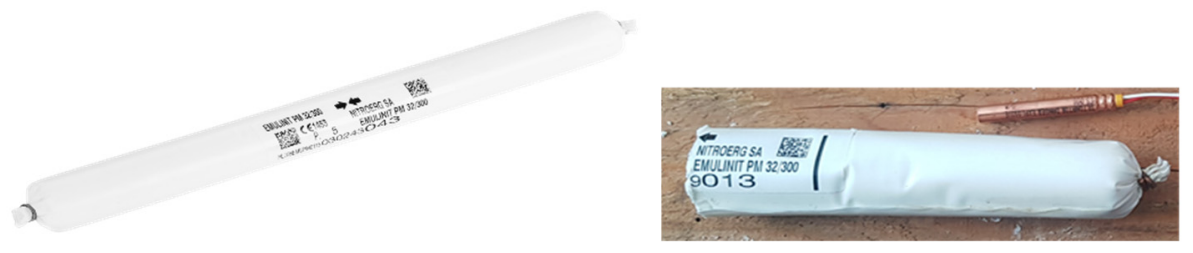

Fig. 5. Emulinit PM permissible explosive, whole and sectioned cartridge.

In the testing tunnel of the Explosives Polygon, a number of 20 tests were performed to verify the safety against the air-methane atmosphere of a load of 1.050 gr. of explosive Emulinit PM and as well as a number of 20 tests to verify the safety against the air - methane - coal dust atmosphere for the same explosive load. No ignition was recorded, the explosive passing the test [6].

Also, a number of 3 tests were performed in order to verify the initiation of a load of 1.050 gr. explosive Emulinit PM, freely suspended and initiated with a line of detonating cord Riocord PS - 6 gr. The explosive was not initiated by the detonating cord [6].

\subsection{Experimental undergound blasts with the use of Emulinit PM explosive}

The experimental blasting works took place at the Vulcan and Livezeni mines. At the Vulcan mine, a number of 30 blasting were performed, out of which 10 blasts in transversal galleries, 10 blasts in directional galleries and 10 blasts in long walls. At the Livezeni mine, a number of 10 blasting works were carried out in the collecting gallery.

As peculiarities of the blasting works practiced in the two mines was the limitation to $500 \mathrm{gr}$. of the explosive charge in the mine hole and the alternative use of 7 consecutive delay steps of electric millisecond detonators, respectively $1-7$ and $8-14$. For safety reasons it is limited to 
blast a maximum of two rows of holes in the coal long front, as well as blasting only of $2 / 3$ of the collector gallery profile $[1,2]$.

The performing of the experimental blasting works was made starting from the following premises:

- use as a reference the currently framework blasting patterns and taking into account the main types and dimensions of mining works in the mine;

- following the preliminary experimental blasts results, setting new blasting parameters number of holes, length of holes, amount of explosive per hole, delay distribution;

- monitoring the gas emissions after the blasting process;

- establish the proper quantity of explosive pe hole and per blast round.

Starting from the current drilling \& blasting framework patterns applied in the two mines with the use of the permissible explosive Metanit Special E7H, the first experimental blasts were made only by varying the quantities of Emulinit PM explosive in the mine hole, respectively quantities of $300 \mathrm{gr}, 450 \mathrm{gr}$. and $600 \mathrm{gr}$. / hole.

Compared to the frame blasting patterns used for digging the galleries, blasting variants were tried with a $10-15 \%$ reduction in the number of holes on the front, with the use of $300-450$ 600 gr. of explosive in the hole or altering the quantities of explosive loaded in the cut holes and at the bottom side of the fronts compared to those loaded in the stopping and profiling holes, respectively 450 gr. with 300 gr., 600 gr. with 300 gr. and 600 gr. with 450 gr.

Quantities of 300 - 450 gr. of explosive in the hole were used for blasting in coal long walls, 450 gr. in the holes in the row from the bottom side and 300 gr. in the rest of rows.

The parameters with reference to the results of the blasting works which were monitored breaking efficiency (advance), profiling of the mining face at walls and roof, granulometry of the blasted rock, distance of throwing of the blasted rock, disposition / geometry of the blasted rock from the front face, presence and the length of the remaining at the bottom of the blasted holes, the granulometry of the blasted rock and the distribution by granulometric classes [7-10].

The results of the performed works were characterized by the following parameters (Figures 6, 7 and 8):

- breaking efficiency / advance ratio $=0.9-1.0$;

- profiling of mining construction on walls and roof: good to verry good;

- granulometry of the blasted rock: $70-80 \%$ in the range of $0-200 \mathrm{~mm}$; $20-25 \%$ in the range of $200-400 \mathrm{~mm}$;

$5 \%$ in the range of $400-600 \mathrm{~mm}$.

- throwing distance of the blasted rock: $4-6-9 \mathrm{~m}$;

- height of disposal of the blasted rock from the front face: $1.5-1.8 \mathrm{~m}$;

- low volume of blasted fumes and evacuated by the ventilations system in a time frame bellow 15 minutes.
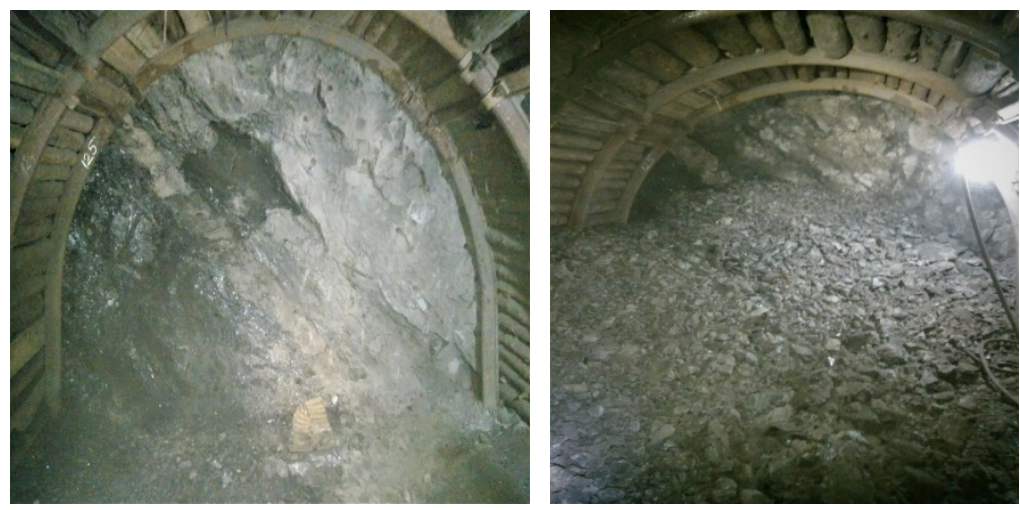

Fig. 6. Directional gallery in mixed coal \& rock face, before and after blasting. 

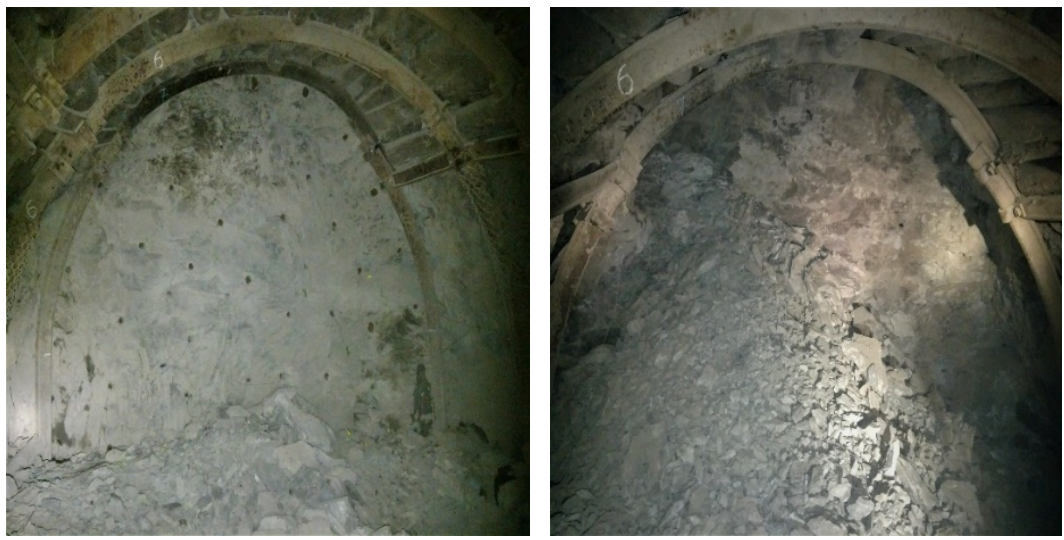

Fig. 7. Transverse gallery in rock face, before and after blasting.

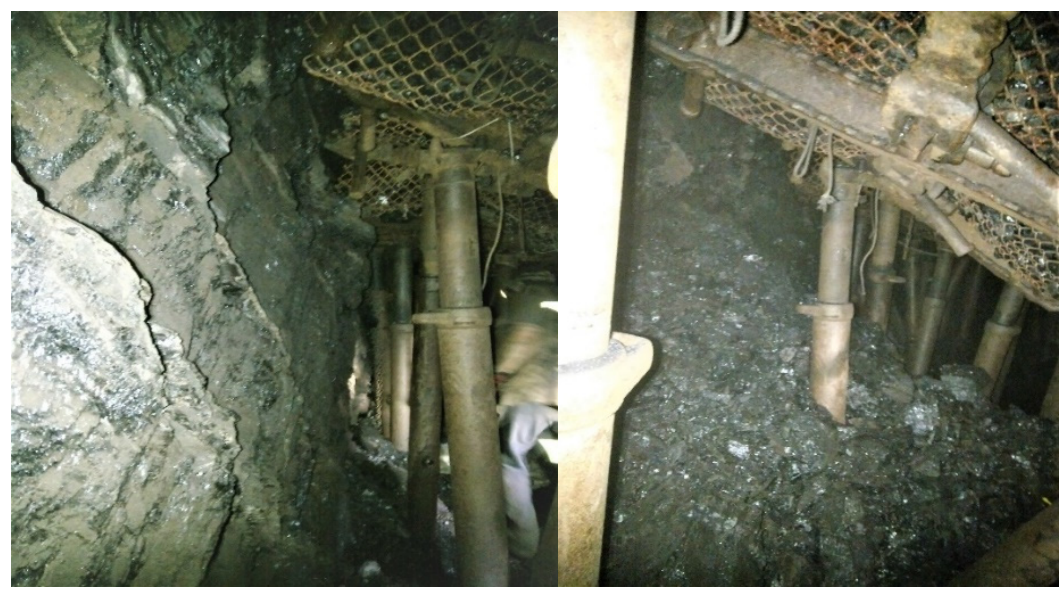

Fig. 8. Coal long wall face, before and after blasting.

\subsection{Technological and safety recommendations for the execution of blasting work}

\subsubsection{Technological recommendation}

\section{Hole diameter}

Due to the drilling technology and the explosives used, the mine holes must have a diameter between $40-42 \mathrm{~mm}$.

\section{Hole length}

The length of the holes must be correlated with the length of the explosive charge so as to ensure the requirements regarding the length of the stemming.

Hole spacing

The minimum distance between the holes must be $0.5 \mathrm{~m}$.

In hole explosive charge construction

The construction of the load will be carried out in the continuous version with rear priming. It will be ensured that the length of the load is dimensioned so as to respect the requirements regarding the minimum stemming length.

The amount of explosive in the hole

The amount of explosive in the hole is limited to a maximum of $600 \mathrm{gr}$. 
Initiation of holes and delay order

The initiation of the holes will be done with permissible millisecond electric detonators, with a delay interval of $75 \mathrm{~ms}$ between two adjacent holes capable of influencing each other, respectively ensuring between the first and last charge that can be fired in the blast face of a delay interval of $200 \mathrm{~ms}$ in coal and $400 \mathrm{~ms}$ in other rocks.

\subsubsection{Safety recommendations}

Permissible explosives and millisecond electrical detonators may only be used in methane mines after the production batch has been certified/verified by a European notified body.

Millisecond electric detonators used in methane mines must have a probability of ignition of up to $4 \%$ of the number of detonators tested.

Emulinit PM to be used in accordance with the recommendations in the field of temperatures: $-10 \div+50^{\circ} \mathrm{C}$. It is allowed to use the material at a maximum temperature of $+60^{\circ} \mathrm{C}$, at the same time, the explosive material cannot be left loaded in the holes mine more than 5 hours. The explosive material after this period still retains its explosive properties, but its parameters may worsen [11].

Emulinit PM cartridges can be divided as close as possible to the indicator that shows half of the load $\longrightarrow$; follows [11]:

- the surface on which the division will be carried out must be clean, free of impurities that may adhere to the exposed explosive material;

- the tool (knife) with which the division will be carried out must be made of anti-spark material and sharp, so that the cutting line is as smooth as possible, free of deformations and leakage of explosive material outside the edge of the coating;

- when loading the fronts with explosive, the explosive cartridges will be divided before inserting them in the mine hole. Care will be taken to ensure that no explosive cartridges remain divided after the holes have been loaded;

- it is forbidden to store divided loads.

For initiation use permissible detonators containing min. 0.6 gr. PETN initiation charge or permissible detonating cord with a minimum linear load of $8 \mathrm{gr} . / \mathrm{lm}$.

\section{Conclusions}

The experiments presented in this article have led to the identification of solutions for carrying out the blasting work and the establishment of measures to allow the use of the permissible emulsion Emulinit PM in a safe and efficient manner. Following the analysis of the results of the experimental blasting works, it turned out that they are at higher values compare with the results at the use of Metanit Special E7H explosive type.

The most appropriate blasting patterns which can be applied have with less $10 \%$ number holes and with a charge range per hole from 300 gr. up to 600 gr. of Emulinit PM.

Further test has to be performed in order to define the optimum power consumption and as well as to find a solution of use of a proper permissible detonating cord in order to initiate the emulsion explosive.

\section{References}

1. Technical documentation for mining method applied at Vulcan and Livezeni mines, Energy and Coal Company, Hunedoara, Romania, (2020)

2. Regulation for occupational safety and health, Energy and Coal Company, Hunedoara, Romania, (2018) 
3. Specific labour protection rules for the storage, transport and use of explosive materials, INSEMEX Petrosani, Romania, (1997)

4. W.W. Von Heinz, Sprengtechnik, Essen, Germany, 125 - 136 (1984)

5. P.A. Persson, R. Holmberg, J. Lee, Rock Blasting and Explosives Engineering, CRC Press Inc., USA, 233-259 (1994)

6. Explosive test reports, INSEMEX Petrosani, Romania, (2021)

7. R. Laszlo et al., Establishing the security requirements for the execution of the blasting works at Tg. Ocna Salt Mine, with the use of ordinary and permissible explosives, Research project, INSEMEX Petrosani, Romania, 14 - 20 (2019)

8. S. Becut et al., Utilization of the permissible detonating cord in the conditions of using long holes in the method of exploitation with the collapse of coal and surrounding rocks, Research project, INSEMEX Petrosani, Romania, 10 - 26 (2001)

9. C. Ciocoiu, N. Heljiu, R. Laszlo, N. Serban, Framework blasting patterns for the types of mining works with profiles of over $12.5 \mathrm{~m}^{2}$, in the geological-mining conditions of the mines from the Jiu Valley, in order to increase the advancement step and to optimize the specific explosive consumption, Research project, INSEMEX Petrosani, Romania, 7-12 (1992)

10. R. Laszlo, C. Revitea, D. Andrei, Improving the blasting patterns, applied in the field conditions specific to the mines in the Campulung Muscel area, in order to increase the efficiency in safe blasting conditions, Research project, INSEMEX Petrosani, Romania, 4 - 9, 15 - 17 (1992)

11. Product catalogue - Emulinit PM, Nitro Erg, Poland, (2015) 